\title{
Brand Conversation: How Brands Can Leverage Online Interactions with Consumers: An Abstract
}

\author{
Andria Andriuzzi
}

\begin{abstract}
Brands can now express themselves through conversation on social media sites. This research investigates the way brands and consumers use human language in interaction. Alongside other personification techniques, brand conversation can be seen as an attempt to humanize the brand by adopting a human behavior. Based on a documentary research, a first study provides a definition of brand conversation and a typology of brands' conversational strategies depending of their initiator and location. Based on a series of interviews with consumers, a second study shows that conversing brands can be seen to be more human and can improve their image even without the physical presence of a speaker. However, simply being present on social media or personifying the brand will not suffice. To be more human, brands must participate in quality conversation. Consumers evaluate conversation according to its context, content, and form. A third study investigates how managers can improve the quality of their brands' conversations in order to drive positive effects such as positive brand evaluation, word of mouth, and purchase intention. Practitioners are therefore encouraged to develop personalized and valuable conversations in order to strengthen the links between brands and consumers.
\end{abstract}

References Available Upon Request

Acknowledgment The author would like to thank Professor Géraldine Michel, Director of Chaire Marques \& Valeurs, for her kind advice and Xavier Cazard of Entrecom for his support.

\footnotetext{
A. Andriuzzi $(\square)$

GREGOR-IAE de Paris, Université Paris 1 Panthéon-Sorbonne, Paris, France

e-mail: andria@andriuzzi.com
} 